\title{
POTENTIODYNAMIC BEHAVIOUR OF GRAPHITE AND PLATINUM ELECTRODES IN SODIUM NITRITE-POTASSIUM NITRITE MELTS
}

\author{
M. G. Sustersic, W. E. Triaca and A. J. Arvia \\ Instituto de Investigaciones Físicoquimicas Teóricas y Aplicadas, División Electroquímica, Facultad de \\ Ciencias Exactas, Universidad Nacional de La Plata, La Plata, Argentina \\ (Received 8 February 1973 ; in final form June 1973)

\begin{abstract}
Ahstract - The potentiodynamic bchaviour of graphitc and platinum clectrodes was studicd in alkaline nitrite melts. No appreciable corrosion of graphite was observed, due to the apparently low concentration of highly oxidising species. Rate processes such as $\mathrm{NO}_{2}^{-}$ion oxidation. $\mathrm{NO}_{2}$ reduction and $\mathrm{OH}^{-}$ion oxidation were studied and interpreted with formerly discussed reaction pathways.
\end{abstract}

\section{INTRODUCTION}

The literature on the electrochemistry of molten nitrites is rather scarce, particularly in comparison with that corresponding to other oxoanion-containing melts such as nitrates, sulphates or carbonates. Previous reports mainly refer to polarographic studies of nitrite ion dissolved into the nitrates[1-3]. The kinetics of the anodic oxidation of nitrite ion either as pure or dissolved in nitrate eutectics depends on the electrode material[4-6].

In molten alkaline nitrates graphite anodes corrode, while this process does not appreciably occur in alkaline nitrite melts. The corrosion process in the nitrate melts has been related to the formation of a surface oxide on graphite which can be built and reduced during repetitive potentiodynamic experiments[7]. Its occurrence has been attributed to the presence of the various oxygen ion species present in the molten nitrates.

Following the pattern of previous work, the study of the potentiodynamic behaviour of graphite and platinum electrodes was extended to molten alkaline nitrites.

\section{EXPERIMENTAL}

The experimental setup, electrode preparation and techniques were described in previous publications $[7,8] \mathrm{NaNO}_{2}-\mathrm{KNO}_{2}(1: 1)$ melts were prepared from high purity chemicals. A platinum $\mathrm{NO}_{2}$ (sat)/ $\mathrm{NO}_{2}^{-}$ electrode was used as a reference electrode. The $\mathrm{NO}_{2}$ saturating the reference electrode compartment was prepared in situ by electrolysing the melt at a constant potential. The working temperature was $236 \pm 1^{\circ} \mathrm{C}$.

\section{RESULTS}

1. Voltammograms run on graphite and platinum from the rest potential towards anodic potentials

The electrochemical reduction of $\mathrm{NO}_{2}$ on platinum exhibits a cathodic current peak at ca $0 \cdot 05-0 \cdot 10 \mathrm{~V}$, while on graphite electrode is at $0.175 \mathrm{~V}$ (Fig. 1). The peak height increases with the potential sweep rate, $v$, and its potential remains independent on $v$.

If the melt is previously cathodised at $-1.5 \mathrm{~V}$ for $1 \mathrm{~min}$ and then voltammograms are run at 5, 10 or $50 \mathrm{mV} / \mathrm{s}$ from -0.3 to $0.3 \mathrm{~V}$, an anodic current peak occurs during the first sweep, either on platinum (at $c a$ $0.175 \mathrm{~V}$ ) or on graphite (at $c a 0 \mathrm{~V}$ ), (Figs. 2 and 3 ). With

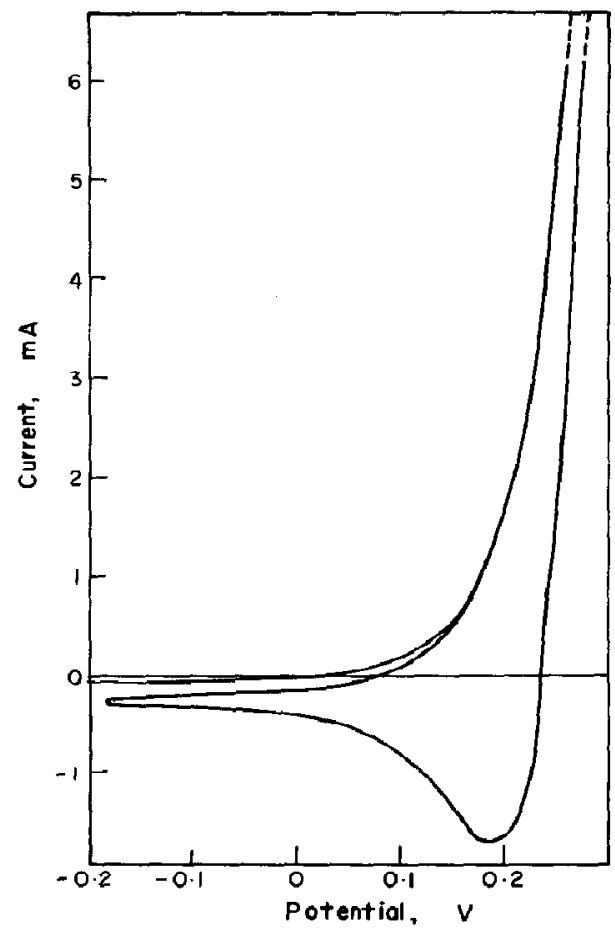

Fig. 1. Voltammograms run with the graphite/nitrite system at $50 \mathrm{mV} / \mathrm{s}$ covering the anodic potential region, $236^{\circ} \mathrm{C}$. 


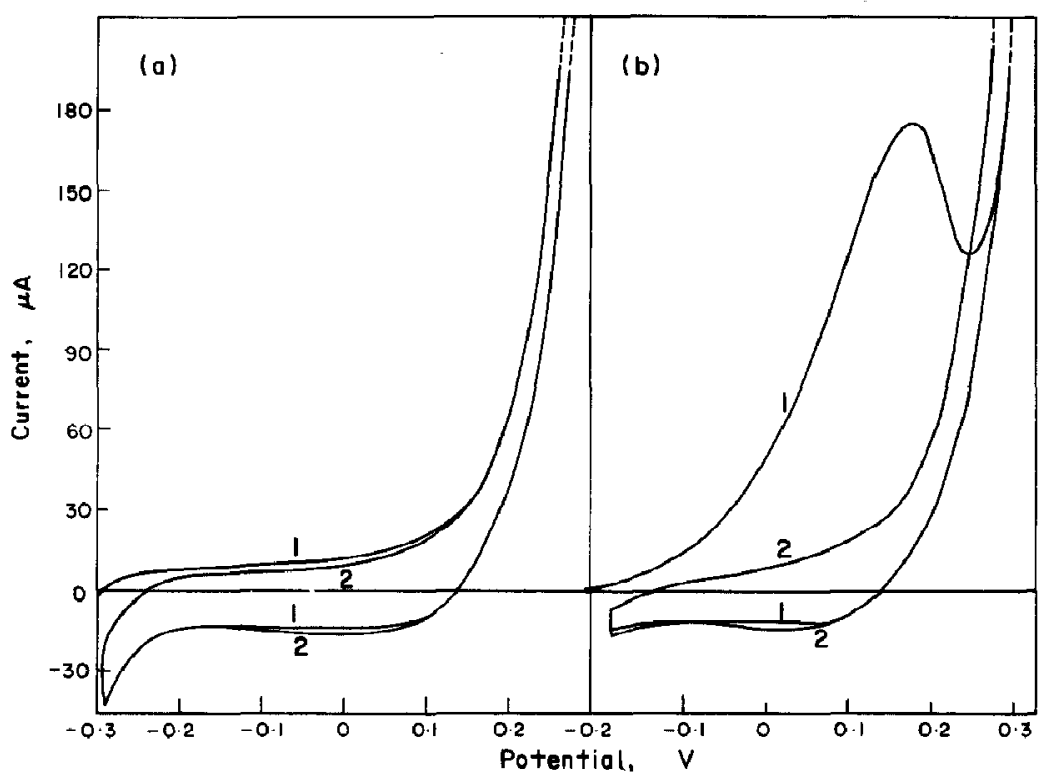

Fig. 2. Effect of previous cathodisation at $-1.0 \mathrm{~V}$ on the first and successive cycles (a). platinum/nitrite, (b), blank, $50 \mathrm{mV} / \mathrm{s}, 236^{\circ} \mathrm{C}$.

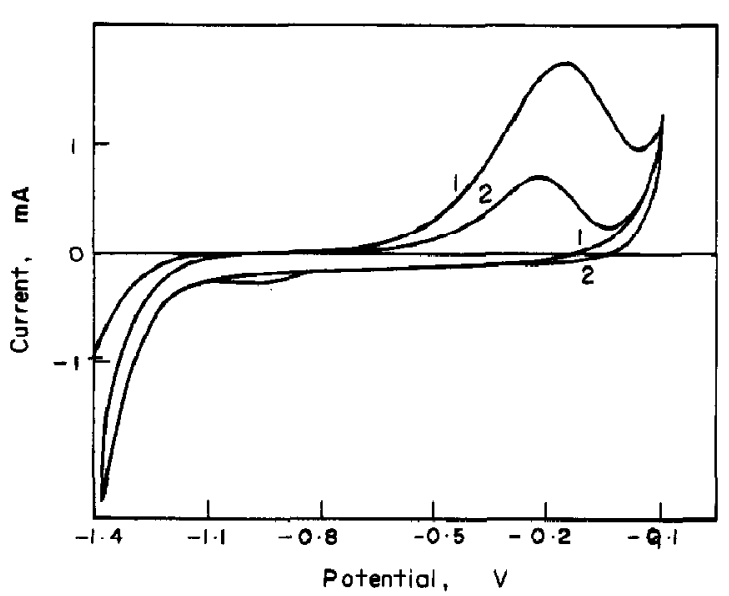

Fig. 3. Voltammograms run from $-1.4 \mathrm{~V}$ up to $+0.1 \mathrm{~V}$, graphite/nitrite, $50 \mathrm{mV} / \mathrm{s}, 236^{\circ} \mathrm{C}$.

graphite electrodes the height of the anodic current peak decreases in the second cycle. Within the region of potential where the anodic peak occurs, the current increases quite markedly when $\mathrm{NaOH}$ is added to the melt, affecting also the current during the returning half-cycle. The current increase prior to the nitrite ion discharge is quite likely related to the $\mathrm{OH}^{-}$ion oxidation. These experiments demonstrate a high local concentration of basic species are formed at the electrode/melt interface during cathodisation due to the reaction of oxide ions with residual water[9]. The addition of $\mathrm{Na}_{2} \mathrm{O}_{2}$ to the nitrite melt containing traces of water provokes also an increase in the $\mathrm{OH}^{-}$ion oxidation current. This effect, however, is lower than the one obtained with the addition of $\mathrm{NaOH}$ (Figs. 4 and 5).

As shown in the voltammograms, the anodic current peak has no cathodic complementary current peak within the potential range swept. At low potential sweep rates the $\mathrm{NO}_{2}$ reduction peak tends to disappear. The current plateau related to the $\mathrm{OH}$ ion oxidation apparently increases linearly with $v^{1 / 2}$ as expected for a diffusion controlled process. The $\mathrm{OH}^{-}$ ion discharge, however, occurs at potentials closer to that of the $\mathrm{NO}_{2}^{-}$ion oxidation on increasing the potential sweep rate. A similar effect is observed on increasing the $\mathrm{OH}^{-}$ion concentration.

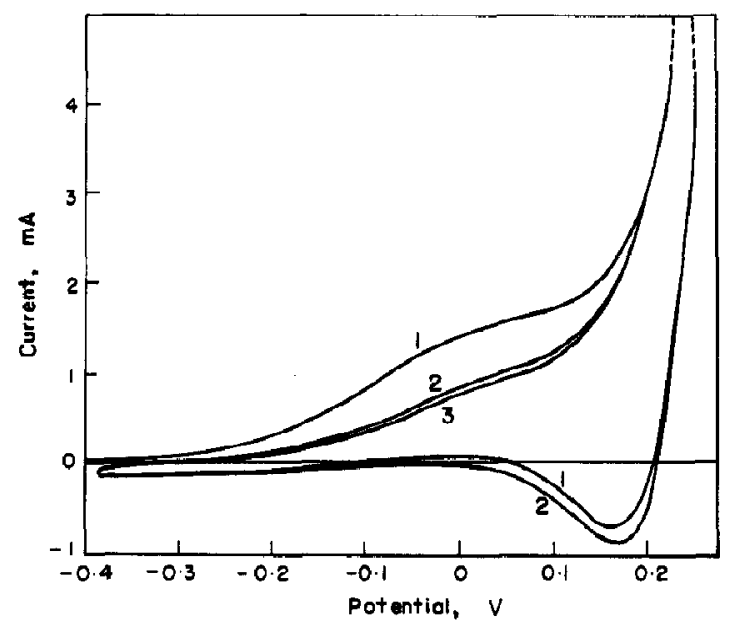

Fig. 4. Voltammograms run after the addition of $\mathrm{Na}_{2} \mathrm{O}_{2}$ $(0.5 \mathrm{M})$, graphite $/$ nitrite, $50 \mathrm{mV} / \mathrm{s}, 236^{\circ} \mathrm{C}$. 


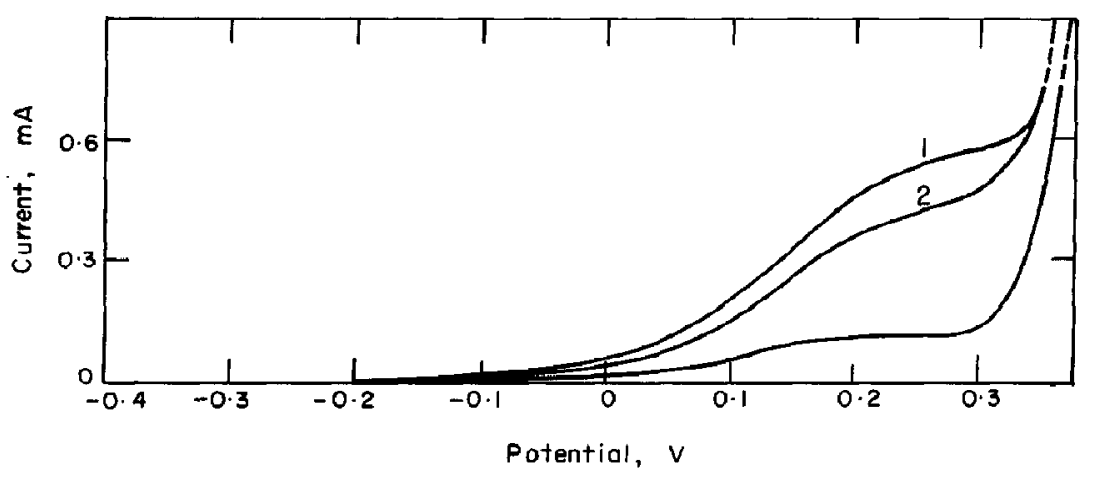

Fig. 5. Voltammograms run after the addition of $\mathrm{Na}_{2} \mathrm{O}_{2}(0.5 \mathrm{M})$, platinum/nitrite, $200 \mathrm{mV} / \mathrm{s}, 236^{\circ} \mathrm{C}$.

\section{Voltammograms run within a larger range of potential}

(i) Platinum electrodes. Cyclic voltammograms were run between -1.7 and $-0.2 \mathrm{~V}$ (Fig. 6). The first voltammogram shows an anodic current peak at $c a$ $-1.35 \mathrm{~V}$, but at $-1.1 \mathrm{~V}$ the current became cathodic again. During the returning half-cycle, a cathodic current peak is found at $c a-0.65 \mathrm{~V}$ and a second one at $c a-1.5 \mathrm{~V}$. The height and position of the anodic and cathodic current peaks at $c a-1.4 \mathrm{~V}$ and $c a-1.5 \mathrm{~V}$, respectively, change during cycling. The potential of the first anodic peak becomes more anodic and that of

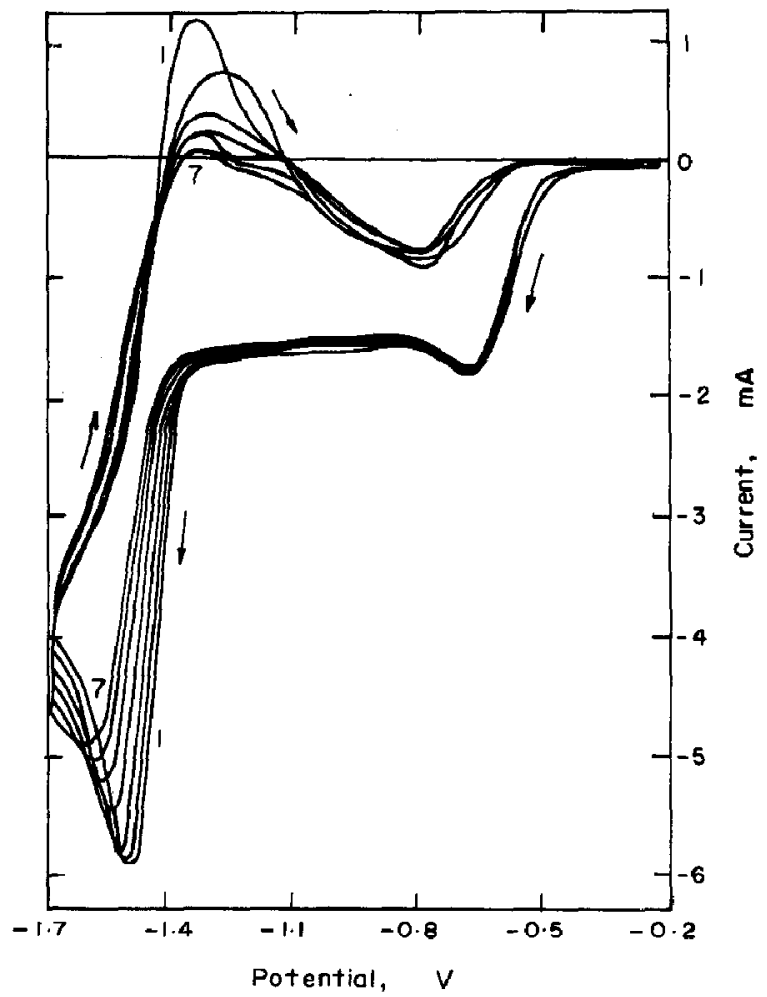

Fig. 6. Repetitive voltammograms covering the cathodic potential region $(-1.7$ to $-0.2 \mathrm{~V})$, platinum/nitrite, $100 \mathrm{mV} / \mathrm{s}, 236^{\circ} \mathrm{C}$. the second cathodic peak shifts towards more cathodic potentials. When these voltammograms are compared to those obtained with alkaline nitrate melts within the same potential range[10], they resemble those current peaks due to the $\mathrm{Na}_{2} \mathrm{O}$ (cathodic) precipitation and its dissolution (anodic), respectively.

The accurrence of the cathodic current peak at ca $-0.65 \mathrm{~V}$ is independent of any pre-electrolysis and $\mathrm{N}_{2}$ saturation of the melt. When the amplitude of the potential sweep is between -1.0 and $0.35 \mathrm{~V}$, the voltammogram exhibits together with the cathodic current peak at $c a-0.65 \mathrm{~V}$, an anodic peak at about $0.115 \mathrm{~V}$, which corresponds to the $\mathrm{OH}^{-}$ion discharge. The cathodic current peak height decreases slightly after cycling, its occurrence depends on the pressure of water in molten nitrates[11]. Its potential becomes more negative when the potential sweep rate increases.

(ii) Graphite electrodes. Figure 7 shows voltammograms swept from -1.5 to $0.35 \mathrm{~V}$ with graphite electrodes. After a previous cathodisation at $-1.5 \mathrm{~V}$, the voltammogram run towards anodic potentials exhibits an anodic current peak at $c a-1.0 \mathrm{~V}$, which probably corresponds to the dissolution of the oxide precipitated during the cathodisation. This peak height decreases with cycling becoming more cathodic. At ca $-0.05 \mathrm{~V}$ the anodic current peak corresponding to the $\mathrm{OH}^{-}$ion oxidation remains unaltered during cycling At $0.3 \mathrm{~V}$ the anodic current increases rather rapidly due to the $\mathrm{NO}_{2}^{-}$ion oxidation. The returning half-cycle shows a cathodic current plateau between $-0.75 \mathrm{~V}$ and $-1.0 \mathrm{~V}$. At $-1.2 \mathrm{~V}$ a small inflexion is observed and finally, the current increases continuously with potential.

\section{Effect of the potential range covered by voltammo- grams on graphite}

Voltammograms run between -0.8 and $-0 \cdot 3 \mathrm{~V}$ exhibit no current peak and they cover a constant area after cycling. When the potential amplitude extends between -0.9 and $0.1 \mathrm{~V}$, an increase of the cathodic current occurs. The anodic current peak that appears during the first cycle related to the $\mathrm{OH}^{-}$ion oxidation, 


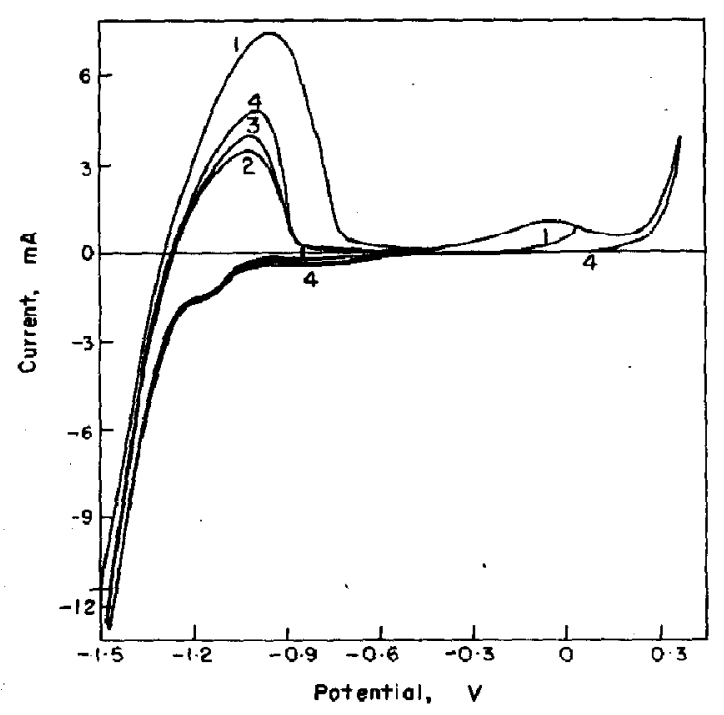

Fig. 7. Repetitive voltammograms covering the cathodic potential region $(-1.5 \mathrm{~V}$ to $0.35 \mathrm{~V})$, graphite/nitrite, $50 \mathrm{mV} / \mathrm{s}, 236^{\circ} \mathrm{C}$.

is no longer observed during the following cycles. When covering the potential range from -1.0 to $0.25 \mathrm{~V}$, a net cathodic current peak appears (Fig. 8) at ca $-0.675 \mathrm{~V}$. It can be compared to the current peak found on platinum at $c a-0.65 \mathrm{~V}$.

The current peak due to the presence of water is better defined after a previous cathodisation and an anodisation up to the potential of the $\mathrm{NO}_{2}^{-}$ion discharge. The electrochemical appears as a process more irreversible on graphite than on platinum electrodes.

\section{Effect of $\mathrm{NO}_{2}$ and $\mathrm{NO}$}

When the melt is saturated with either $\mathrm{NO}_{2}$ or $\mathrm{NO}$, the rest potential of the graphite electrode is nearly $0.1 \mathrm{~V}$. Voltammograms run from -0.3 to $0.175 \mathrm{~V}$ show an initial marked increase of the cathodic current. This effect, however, is less notorious during cycling. The saturation of the graphite/nitrite system with $\mathrm{NO}_{2}$ produces a gas evolution. As in the nitrate melts[7], a chemical attack of graphite is energetically possible, according to any of the following reactions [12]:

$$
\begin{aligned}
\mathrm{NO}_{2}+\mathrm{C} & =\mathrm{NO}+\mathrm{CO} \\
\Delta G_{500}^{\circ} \mathrm{K} & =-32.440 \mathrm{kcal} / \mathrm{mole} . \\
2 \mathrm{NO}_{2}+\mathrm{C} & =\mathrm{CO}_{2}+2 \mathrm{NO} ; \\
\Delta G_{500^{\circ} \mathrm{K}}^{\circ} & =-84.560 \mathrm{kcal} / \mathrm{mole} .
\end{aligned}
$$

If graphite is placed into the melt saturated with $\mathrm{NO}_{2}$, voltammograms run after sweeping out $\mathrm{NO}_{2}$ with $\mathrm{N}_{2}$, exhibit a net increase of area with respect to the voltammograms run in the absence of $\mathrm{NO}_{2}$ saturation. This increase of area is, however, smaller than the one previously reported in nitrate melts[7].

- No net gas evolution was noticed when the melt was saturated with NO.

\section{The addition of water}

To increase the water content in the nitrite melt. stoichiometric amounts of $\mathrm{NaOH}$ and $\mathrm{KHSO}_{4}$ were added. Voltammograms run at $50 \mathrm{mV} / \mathrm{s}$ between -1.0 and $0.2 \mathrm{~V}$, either on platinum or graphite, exhibit

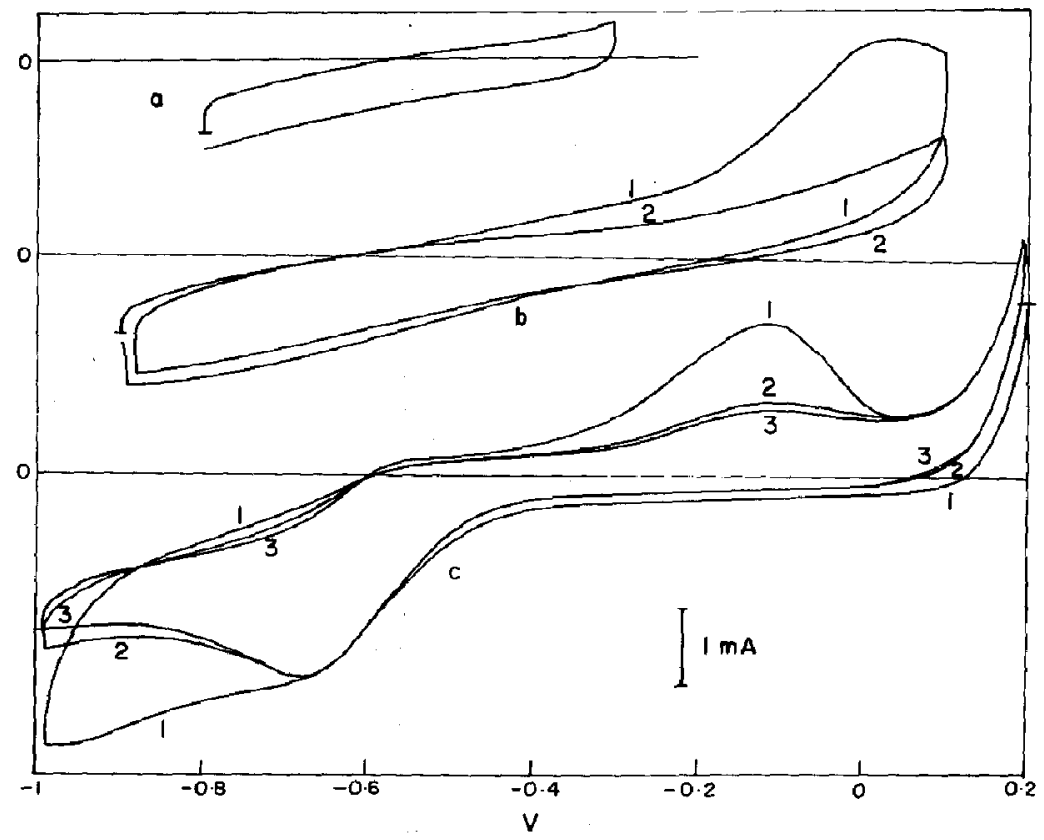

Fig. 8. Effect of three potential sweep amplitudes on voltammograms run with graphite/nitrite at $50 \mathrm{mV} / \mathrm{s}, 236^{\circ} \mathrm{C}$ 
a marked increase of the residual current wave at $-0.65 \mathrm{~V}$. The wave approaches a peak shape at lower water contents. On graphite, however, this cathodic peak is not so well defined as on platinum.

\section{The simultaneous addition of $\mathrm{Na}_{2} \mathrm{O}_{2}$ and $\mathrm{NO}$}

The addition of either $\mathrm{NO}$ or $\mathrm{NO}_{2}$ to the nitrite melt containing $\mathrm{Na}_{2} \mathrm{O}$, produces only a net decrease of the $\mathrm{OH}^{-}$ion oxidation current, both on platinum and graphite. Within the potential range $-0-4-0.5 \mathrm{~V}$, only the $\mathrm{NO}_{2}$ reduction current peak is observed

\section{DISCUSSION}

\section{General considerations}

Voltammograms obtained with fresh and carefully dried $\mathrm{NaNO}_{2}-\mathrm{KNO}_{2}$ melts, either on graphite or platinum electrodes are simpler than those already reported for the alkaline nitrate melts at low temperature $[7,13]$. However, they approach the characteristics of those run with molten alkaline nitrates at high temperatures.

A noticeable difference between the voltammograms run with molten nitrites and with molten nitrates at $236^{\circ} \mathrm{C}$ is the absence of any clearly defined current peak (either anodic or cathodic) in the former melt, which could be attributed to the electrochemical formation or reduction of a graphite oxide. This behaviour is consistent with the apparent minor corrosion of graphite in nitrite melts as inferred from the cyclic voltammograms covering different potential ranges.

The following discussion refers to the reactions occurring within different potential ranges, their kinetics and likely reaction pathways.

2. The electrochemical nitrite ion oxidation and $\mathrm{NO}_{2}$ reduction

The main overall reaction occurring either on platinum or graphite at anodic potentials higher than $0.1 \mathrm{~V}$ is the $\mathrm{NO}_{2}^{-}$ion discharge according to:

$$
\mathrm{NO}_{2}^{-}=\mathrm{NO}_{2}+e \text {. }
$$

The corresponding stationary anodic current increases with potential according to a Tafel equation, both for platinum and graphite $[5,6]$. For both electrodes the anodic Tafel slopes derived from the voltammograms at $v \rightarrow \mathbf{O}$, roughly approach the values already reported under stationary conditions. The cathodic current peak related to the reduction of $\mathrm{NO}_{2}$ on graphite increases with $v$, but the peak potential remains practically constant.

The reaction mechanisms discussed earlier for the stationary anodic oxidation of $\mathrm{NO}_{2}^{-}$ion either or graphite or on platinum electrodes essentially involve a reaction pathway where a fast initial electron transfer step is followed by a relatively slow chemical reaction. The latter may be either a radical desorption reaction which follows the initial reversible electron transfer step or the reaction:

$$
\mathrm{NO}_{2}+\mathrm{NO}_{2}^{-}=\mathrm{NO}+\mathrm{NO}_{3}^{-} \text {. }
$$

Reaction (2), referred to $\mathrm{NaNO}_{z}$ at $500^{\circ} \mathrm{K}$, has a $\Delta G^{\circ}=-18.325 \mathrm{kcal} / \mathrm{mole}$.

Most of the voltammogram related to $\mathrm{NO}_{2}$ reduction can be reproduced with the rate equation of a reversible process $\lceil 14\rceil$ applied to the reaction:

$$
\mathrm{NO}_{2}+e=\mathrm{NO}_{2}^{-} \text {. }
$$

The height of the $\mathrm{NO}_{2}$ current peak decreases when the melt contains $\mathrm{NaOH}$. Correspondingly, the height of the $\mathrm{OH}^{-}$ion oxidation peak at $0-0.1 \mathrm{~V}$, also diminishes after repetitive cycling when the potential amplitude covers the region of $\mathrm{NO}_{2}^{-}$ion oxidation. These simultaneous effects are related to the overall reaction:

$$
2 \mathrm{NO}_{2}+2 \mathrm{NaOH}=\mathrm{NaNO}_{2}+\mathrm{NaNO}_{3}+\mathrm{H}_{2} \mathrm{O}
$$

which explains the elimination of basic species from the melt by $\mathrm{NO}_{2}$. Species such as $\mathrm{O}^{2-}$ ion will probably react with $\mathrm{NO}_{2}$, yielding $\mathrm{NO}_{3}^{-}$and $\mathrm{NO}_{2}^{-}$ions according to:

$$
2 \mathrm{NO}_{2}+\mathrm{Na}_{2} \mathrm{O}=\mathrm{NaNO}_{3}+\mathrm{NaNO}_{2}
$$

For reaction (5), $\Delta G^{\circ}$ at $500^{\circ} \mathrm{K}$ is $-66.812 \mathrm{kcal} / \mathrm{mole}$.

3. The cathodic reduction peak due to the presence of water

The electrochemical reduction of either $\mathrm{HNO}_{2}$ or $\mathrm{HNO}_{3}$ occurs within the potential range -0.3 to $-0.8 \mathrm{~V}$, both for graphite and platinum electrodes, yielding a gas, probably hydrogen. The peak height increases with the water content, but at a relatively high concentration of the latter a limiting current is approached. When the reduction occurs on platinum, the returning half-cycle exhibit the $\mathrm{OH}^{-}$ion oxidation current peak. These facts can be explained in terms of the following overall reactions:

$$
\begin{aligned}
& 2 \mathrm{HNO}_{2}+2 e=\mathrm{H}_{2}+2 \mathrm{NO}_{2}^{-} \\
& 2 \mathrm{HNO}_{3}+2 e=\mathrm{H}_{2}+2 \mathrm{NO}_{3}^{-}
\end{aligned}
$$

A possible side reaction such as $\mathrm{NO}_{2}^{-}$ion reduction by hydrogen atoms seems to be irrelevant $[11,15]$.

The voltammograms run on platinum suggest that the reduction corresponds to an irreversible diffusion controlled process, reaction (6) involving a fast electron transfer step followed by a slow chemical reaction. For such an electron transfer-chemical reaction mechanism, the peak current depends on the $k_{f} / a$ ratio, where $k_{f}$ is the rate constant of the chemical step and $a=z F v / R T[14]$. The cathodic voltammogram can be reproduced up to nearly $-0.7 \mathrm{~V}$ with the following data: $C=2.4 \times 10^{-6} \mathrm{~mole} / \mathrm{cm}^{3}$; Tafel slope $=$ $2 R T / F ; k_{f} / a=4$ and the diffusion coefficient of the reacting species in the nitrite melt equal to $1.9 \times$ $10^{-5} \mathrm{~cm}^{2} / \mathrm{s}$ at $502^{\circ} \mathrm{K}$, as that of water in molten alkaline nitrate[11] (Fig. 9). 


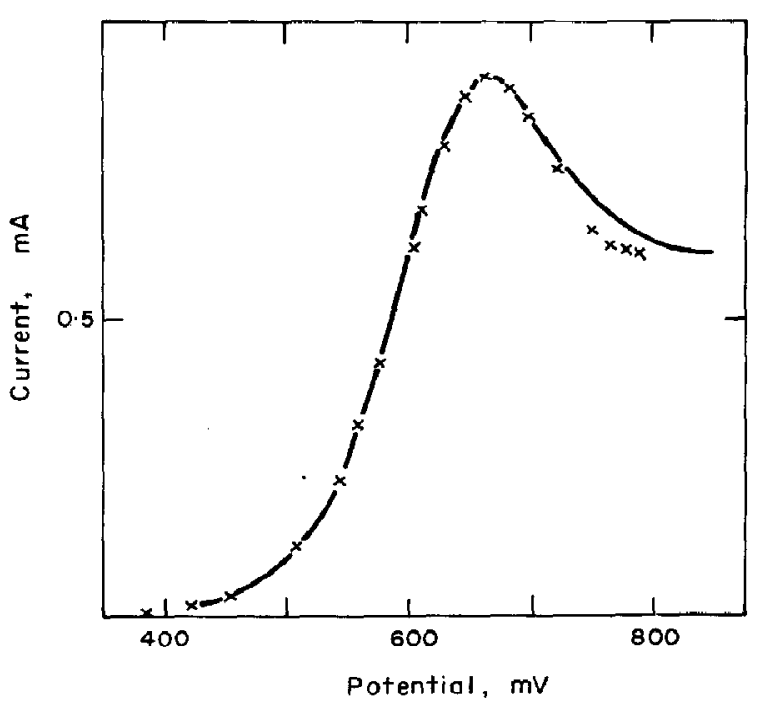

Fig. 9. Comparison of the experimental voltammogram for the reduction process $(6 a)$ or $(6 b)$ with the theoretical one derived for a diffusion control reaction involving an electron transfer followed by a chcmical reaction: platinum/nitritc, $100 \mathrm{mV} / \mathrm{s},\left(k_{f} / a\right)=4,236^{\circ} \mathrm{C}$.

The voltammograms due to the presence of water cover a potential range from -0.2 to $-0.9 \mathrm{~V}$ thereabouts and comprise a Tafel slope close to $R T / F$. They can be reasonably reproduced down to $-0.75 \mathrm{~V}$ with the rate equation for an irreversible electrochemical process under diffusion control[14] with a transfer coefficient equal to 0.5 and the number of electrons involved up to the rate determining step equal to one (Fig. 10). Therefore, the kinetic parameters related to the reduction process depend on the electrode material, the reaction rate appearing slower on graphite than on platinum.

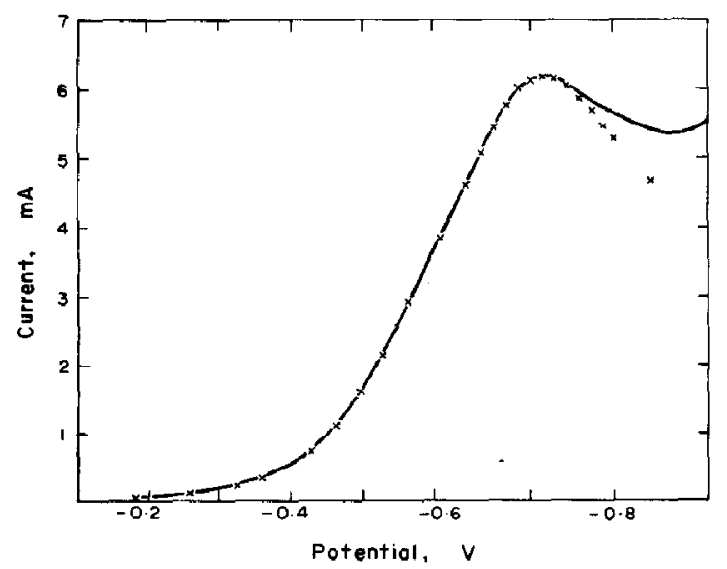

Fig. 10. Comparison of the experimental voltammogram for the reduction process (6a) or (6b) with the theoretical one derived for a diffusion controlled irreversible reaction; graphite/nitrite, $50 \mathrm{mV} / \mathrm{s}, 235^{\circ} \mathrm{C}$.

\section{The $\mathrm{OH}^{-}$ion oxidution}

The portion of the voltammograms related to the oxidation of $\mathrm{OH}^{-}$ion, either on platinum or graphite, exhibit a linear $E / \log I$ relationship at potentials preceding the corresponding current peaks. At $v=$ $5 \mathrm{mV} / \mathrm{s}$ the Tafel slope is close to $2 R T / F$. This suggests the $\mathrm{OH}^{-}$ion discharge is an activated electrochemical process related to water formation, which can be put in the following way:

$$
\begin{aligned}
\mathrm{OH}^{-}+S & =(\mathrm{OH}) \mathrm{S}+e \\
2(\mathrm{OH}) \mathrm{S} & =\mathrm{H}_{2} \mathrm{O}+\mathrm{S}(\mathrm{O}),
\end{aligned}
$$

where $S$ means an active site either on graphite or on platinum. Under non-stationary conditions and a negligible surface coverage by $\mathrm{OH}$ radicals, step (7a) is probably rate-determining.

On cathodising previously a water containing melt, the $\mathrm{OH}^{-}$ion concentration increases since the following equilibrium:

$$
\mathrm{O}^{2-}+\mathrm{H}_{2} \mathrm{O}=2 \mathrm{OH}^{-}
$$

is largely displaced to the right[9].

\section{The electrochemical reduction of $\mathrm{NO}_{2}^{-}$ion}

The reduction of $\mathrm{NO}_{2}^{-}$ions occurs within the potential range from -1.0 to $-1.5 \mathrm{~V}$, yielding an increasing concentration of basic species in the melt. It can be interpreted with different overall reactions:

$$
\begin{aligned}
\mathrm{NO}_{2}^{-}+e & =\mathrm{NO}+\mathrm{O}^{2-} \\
2 \mathrm{NO}_{2}^{-}+4 e & =\mathrm{N}_{2} \mathrm{O}+3 \mathrm{O}^{2-} \\
2 \mathrm{NO}_{2}^{-}+6 e & =\mathrm{N}_{2}+4 \mathrm{O}^{2-} \\
\mathrm{NO}_{2}^{-}+\mathrm{NO}_{2}+e & =2 \mathrm{NO}+\frac{1}{2} \mathrm{O}_{2}+\mathrm{O}^{2-} .
\end{aligned}
$$

The change of free energy of these reactions at equilibrium are calculated at different oxide ion activities [16]. Any of these reactions yield an accumulation of oxide ions at the electrode/electrolyte interface. This causes the precipitation of sodium oxide on the electrode and the concurrent appearance of the cathodic current peak having the characteristics of those related to the formation of insoluble films. Correspondingly, the anodic peak observed at the highest cathodic potentials is related to the dissolution of the oxide film. So, in this potential region the voltammetric behaviour of molten nitrites is similar to that one already reported for molten nitrates[9]. For the time being, no further quantitative conclusions can be derived from this region of the voltammetric $E-I$ curves.

6. Comparison of the behaviour of platinum and graphite electrodes in molten sodium-potassium nitrites and sodium-potassium nitrates

Molten alkaline nitrites are more stable and less corrosive towards graphite than the corresponding molten nitrates. This difference must be attributed to the relatively higher concentration of $\mathrm{O}_{2}^{2-}$ and $\mathrm{O}_{2}^{-}$ ions in molten nitrates as compared to that in molten nitrites. The ionic composition of the latter causes the 
lack of an appreciable current related to any graphite oxide formation. As already discussed[7], the latter occurs through the formation of the $\mathrm{NO}_{3}$ intermediate by reacting $\mathrm{NO}$ and $\mathrm{O}_{2}^{-}$ion, with the participation of the following equilibrium $[17,18]$ :

$$
\mathrm{O}_{2}^{z^{-}}+2 \mathrm{NO}_{3}^{-}=2 \mathrm{O}_{2}^{-}+2 \mathrm{NO}_{2}^{-} \text {. }
$$

When $\mathrm{O}_{2}^{2-}$ ions are added to the pure nitrite melt, they rcact according to:

$$
\mathrm{O}_{2}^{2-}+\mathrm{NO}_{2}^{-}=\mathrm{NO}_{3}^{-}+\mathrm{O}^{2-}
$$

leaving no possibility of $\mathrm{NO}_{3}$ generation at the interface and, therefore, no drastic oxidation of graphite occurs. Hence, the participation of the $\mathrm{O}_{2}^{-}$ion in the process is clearly established.

The preceding discussion explains also why at high temperatures both the platinum/nitrate and the graphite/nitrate systems approach the behaviour of the corresponding nitrite systems, since as temperature increases both melts attain a common ionic composition.

The distinction between graphite and platinum electrodes in the nitrite melt mainly resides in the kinetics of the various processes occurring on them. It appears that most of the reactions, either anodic or cathodic, are relatively faster on platinum than on graphite, as it was concluded from previous studies of these systems under stationary conditions.

Acknowledgement-This work is part of the research program of the Electrochemistry Division of INIFTA, sponsored by the Universidad de La Plata, the Consejo Nacional de Investigaciones Cientificas y Téunicas of Argenlina and the Comisión de Investigaciones Científicas de la Provincia de Buenos Aires. M. G. Sustersic thanks the CIC for the scholarship granted.

\section{REFERENCES}

1. P. G. McCormick and H. S. Swofford, Jr., Anal. Chem. 41, 146 (1969).

2. G. G. Bombi, R. Freddi and M. Fiorani, Annls Chim. 56, 759 (1966).

3. Yu. S. Lyalikov, Zh. analit. Khim. 8, 38 (1953).

4. A. J. Calandra and A. J. Arvía, Electrochim. Acta 11, 1173 (1966).

5. A. J. Arvía and A. J. Calandra, Electrochim. Acta 12, 1441 (1967).

6. M. E. Martins, A. J. Calandra and A. J. Arvía, Electrochim. Acta 15, 111 (1966).

7. M. G. Sustersic, W. E. Triaca and A. J. Arvía, Electrochim. Acta 19, 1-17 (1974).

8. G. Paus, A. J. Calandra and A. J. Arvia, And. Soc cient. Argent. 192, 35 (1971).

9. J. Jordan, W. B. McCarthy and P. G. Zambonin, Molten Salts, Characterisation and Analysis (edited by $\mathrm{S}$. Mamentov), Dekker, New York (1969).

10. P. G. Zambonin, J. electroanal. Chem. 24, 365 (1970).

11. P. G. Zambonin, U. L. Cardetta and G. Signorile, $J$. electroanal Chem. 28, 237 (1970).

12. A. J. Arvia and W. E. Triaca, Anal. Asoc. quim. Argent. 56, 33 (1968)

13. L. E. Topol, R. A. Ostcryoung and J. H. Christic, J. phys. Chem. 70,857 (1966).

14. M. M. Nicholson and I. Shain, Anal. Chem. 36, 706 (1964).

15. J. Goret and B. Trémillon, Bull. Soc. chim. Fr. 67 (1966).

16. S. L. Marchiano and A. J. Arvia, Electrochim. Acta 17, 861 (1972).

17. P. G. Zambonin and J. Jordan, J. Am. chem. Soc. 91, 2225 (1969).

18. J. Jordan, J. electroanal. Chem. 29, 127 (1971). 